\title{
Magnetic Colloids from Magnetotactic Bacteria: Chain Formation and Colloidal Stability
}

\author{
Albert P. Philipse* and Diana Maas ${ }^{\dagger}$ \\ Van't Hoff Laboratory for Physical and Colloid Chemistry, Utrecht University, \\ Debye Institute, Padualaan 8, $3584 \mathrm{CH}$ Utrecht, The Netherlands \\ Received J une 21, 2002. In Final Form: September 10, 2002
}

\begin{abstract}
Single-domain magnetite $\left(\mathrm{Fe}_{3} \mathrm{O}_{4}\right)$ crystals, harvested from magnetotactic bacteria, di splay on transmission electron micrographs the cluster morphologies (folded chains, flux-closure rings) predicted for magnetic coll oids with domi nant di polar attractions. Thesestrong attractionsare responsi blefor thelinear magnetite chains inside bacteria but do not affect the colloidal stability of the bacteria, as confirmed by analytic sedimentation experiments. Calculations of the interaction energy between dipole chains show that the magnetic component of the interbacteria interaction is negl igible due to screening of dipolar forces: the bacteria sense only the geomagnetic field but not each other's compass.
\end{abstract}

\section{Introduction}

A striking property of magnetotactic bacteria such as Magnetospirillum magnetotacticum ${ }^{1}$ is their ability to orient themselves in the earth magnetic field. Their compass is a chain of magnetite colloids which keeps the long axis of the bacteria parallel to the field direction. Propelled by their flagella, the bacteria migrate in a net downward direction, following the declination of the field lines of the earth, toward oxygen-poor regions with advantages for survival (biogenic magnetite as ol $d$ as $7 \times$ $10^{8}$ years has been found; ${ }^{2}$ these bacteria indeed survive). Magnetotactic bacteria occur widely in natural sediments from both marine and freshwater habitats. They produce intracellular, membrane-bounded magnetite $\left(\mathrm{Fe}_{3} \mathrm{O}_{4}\right)_{1}{ }^{3}$ greigite $\left(\mathrm{Fe}_{3} \mathrm{~S}_{4}\right),{ }^{4}$ and pyrrhotite $\left(\mathrm{Fe}_{7} \mathrm{~S}_{8}\right)$ particles. ${ }^{5} \mathrm{~A}$ fairly narrow size distribution of particles of colloidal size and specific crystallographic orientations characterize the mineral particles and their enveloping membrane, together called magnetosomes.

Thegeomagneticsensor of thebacteria isalsointriguing from a colloid science point of view. Single-domain magnetite colloids 6 in laboratory-made dispersions ("ferrofluids") have diameters in the range of 5-15 $\mathrm{nm}$, considerably smaller than bacterial magnetite $(\approx 50 \mathrm{~nm})$. Magnetic interactions in ferrofluids are fairly weak, and since these interactions increase quadratically with the particle volume, biogenic magnetite col loids are expected to havequitestrong di polar (magnetic) interactions. Thus it would be interesting to harvest the biogenic magnetite and see, for example, whether (outside bacteria) the biomagnetiteparticles formstructures such as chains and even rings. These are predicted for strong dipoles, ${ }^{8}$ though

\footnotetext{
* Corresponding author.

† Present address: Fuji, Oudenstaart 1, PB 90156, 5000 LJ Tilburg, The Netherlands.

(1) Blakemore, R. P. Science 1975, 190, 377.

(2) Butler, R. F. Pal eomagnetism; Blackwell Scientific: Oxford, 1992.

(3) Blakemore, R. P.; Maratea, D.; Wolfe, R. S. J . Bacteriol. 1979, 140 (2), 720.

(4) Bazylinski, D. A.; Heywood, B. R.; Mann, S.; Frankel, R. B. Nature 1993, 366, 218

(5) Farina, M.; Esquivel, D. M. S.; Lins de Barros, H. G. P. Nature 1990, 343, 256.

(6) Rosensweig, R. E. Ferrohydrodynamics; Cambridge University Press: Cambridge, 1985.

(7) Ewijk, G. A. van Phase behavior of mixtures of magnetic colloids and nonadsorbing polymer. Thesis, Utrecht University, Utrecht, The
} Netherlands, 2001. as far as we know flux-closure rings have never been observed or imaged in $\mathrm{Fe}_{3} \mathrm{O}_{4}$ ferrofluids.

Demonstrating the existence of such dipole structures by el ectron-micrograph imaging was theinitial motivation for our work on bacterial magnetite, in addition to evaluating bacterial cultivation as an alternative to the usual inorganic preparation methods of magnetite colloids. ${ }^{7,9}$ (These methods are quite restrictive with respect to particle size and shape.) We noticed that the bacteria in our study form quite stable (i.e., nonaggregated) dispersions in water. This fol lowed, for example, from the concentration dependence of the rate at which (dead) bacteria settle in the earth gravitational field. Neverthe less, these bacteria possess long backbones of strongly attractive magnets, so the question arose of why these magnets did not affect thecolloidal stabil ity of the bacterial "particles". Our explanation derives from theory ${ }^{10}$ and simulations ${ }^{10,11}$ in theliteraturewhich show that chaining of strong dipoles strongly suppresses further aggregation or phase separation of magnetic colloids.

Although several species of magnetotactic bacteria have been isolated from natural environments, subsequently laboratory culture of most strains is difficult becausethey are obligate microaerophilic. To our knowledge, nearly all information on culturing of magnetotactic bacteria has been acquired from studies on $\mathrm{M}$. magnetotacti cum. ${ }^{12}$ This organism requires microaerobic conditions and may be grown in a chemically defined medium, as described in section 3 . In section 4, we discuss various characterization experiments such as sedimentation and electrophoresis on the cultivated bacterial cells, as well as electron micrographs of structures of magnetic particles released from the cells. I nteractions between (and in) the bacterial magnetite chains are discussed in section 4.7. First, some theoretical aspects are treated in section 2.

(8) J acobs, I. S.; Bean, C. P. In Magnetism; Rado, G. T., Suhl, H., Eds.; Academic Press: New York, 1963; Vol. III.

(9) Cabuil, V.; Perzynski, R. In Magnetic Fluids and Applications Handbook; Berkovski, B., Ed.; Begell House: New York, 1996.

(10) Halsey, T. C.; Toor, W.j . Stat. Phys. 1990, 61, 1257. G.J . Vroege and B. J. de Gans (unpublished results) pointed out to us that this reference contains an error: eq 15 is their corrected version for the result in ref 10 .

(11) Teixeira, P. I. C.; Tavares, J . M.; Telo da Gama, M. M. J . Phys.: Condens. Matter 2000, 12, R411-R434.

(12) Blakemore, R. P.; Blakemore, N. A.; Bazylinski, D. A.; Moench, T. T. Bergey's Manual of Systematic Bacteriol ogy; Williams \& Wilkins: Baltimore, 1989. 


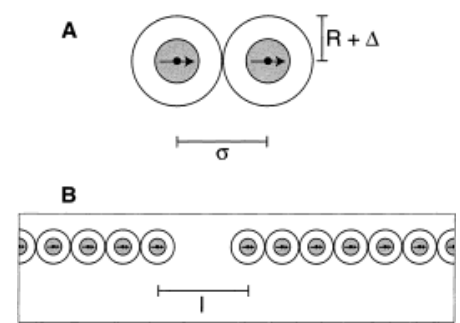

Figure 1. (A) Two dipoles embedded in a sphere of radius $\mathrm{R}$ in a head-to-tail configuration with maximal attraction energy. A nonmagnetic shell thickness $\Delta$ reduces the energy at contact distance $\sigma$. (B) Twoends of rigid dipolechains with an interaction given by eq 9 .

\section{Chains of Magnetic Colloids}

Westart with recapitulating some equations pertinent for (chains of) single-domain magnetic colloids. Suppose two magnetic dipoles with orientation unit vectors $\hat{\mathbf{s}}_{1}$ and $\hat{\mathbf{s}}_{2}$, separated by a center-to-center distance $r$ along the unit vector $\hat{\mathbf{r}}$, are embedded in a solid magnetite particle, covered with an organic (lipid) coating, which allows a closest approach of the dipole centers to a distance $r=\sigma$. The interaction energy for the two dipoles is in units of the thermal energy $\mathrm{kT}$ :

$$
\mathrm{V} / \mathrm{kT}=\lambda(\sigma / \mathrm{r})^{3}\left[\hat{\mathbf{s}}_{1} \cdot \hat{\mathbf{s}}_{2}-3\left(\hat{\mathbf{s}}_{1} \cdot \hat{\mathbf{r}}\right)\left(\hat{\mathbf{s}}_{2} \cdot \hat{\mathbf{r}}\right)\right]
$$

The parameter $\lambda$ measures the contact energy at $r=\sigma$ :

$$
\lambda=\mu_{0} u^{2} / 4 \pi \mathrm{k} T \sigma^{3}
$$

where $\mu_{0}$ is the free-space permeability and $\mu$ is theparticle magnetic moment. For a fully saturated (single-domain) particle of volume $v_{p}$,

$$
\mu=\mathrm{v}_{\mathrm{p}} \mathrm{m}_{\mathrm{s}}
$$

with $m_{s}$ being the saturation magnetization of the bulk material. For magnetic spheres with radius $\mathrm{R}$ and a nonmagnetic coating of thickness $\Delta$ (F igure 1$)$, thedistance of closest approach is $\sigma=2 \mathrm{R}+2 \Delta$. Hence,

$$
\lambda=\frac{\mu_{0} \mathrm{~m}_{\mathrm{s}}^{2} \pi}{18 \mathrm{kT}} \frac{\mathrm{R}^{3}}{(1+\Delta / \mathrm{R})^{3}}
$$

The maximal attraction for two dipoles occurs at a headto-tail configuration (Figure 1):

$$
\mathrm{V}_{\max } / \mathrm{kT}=-2 \lambda \quad \text { for } \mathrm{r}=\sigma
$$

For a collection of dipoles, it is energetically favorable to form linear chains of dipoles; the energy gain to add one dipole to the end of a long linear chain is ${ }^{13}$

$$
\mathrm{V} / \mathrm{kT}=-2 \lambda \sum_{\mathrm{n}=1}^{\infty}\left(1 / \mathrm{n}^{3}\right) \approx-2 \lambda(1.202)
$$

as follows from eq $1 ; n$ labels the dipoles in the chain. For magnetotactic bacteria, it is also interesting to know the energy gain for the fusion of two chains and, more in general, the attraction between chain ends at some finite distance. This attraction can be evaluated as follows. Consider a long, straight di polechain with its head-sphere a distancel removed from the center of the tail-sphere of

(13) Lavender, H. B.; I yer, K. A.; Singer, S. J . J . Chem. Phys. 1994, $101,7856$.

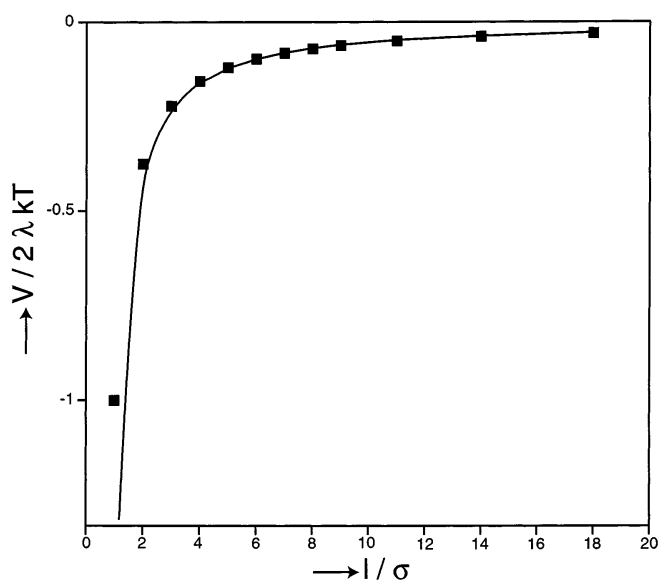

Figure 2. Numerical solution (drawn line) of eq 9 by summing up to $p=1000$. Squares represent theapproximate interaction in eq 10.

another chain, the two rigid chains being in oneline with their main axes (see Figure 1B). The interaction energy between two dipoles from different chains is (see eq 1)

$$
\frac{\mathrm{V}_{\mathrm{n}, \mathrm{m}}}{\mathrm{kT}}=-2 \lambda\left(\frac{\sigma}{\mathrm{I}+\mathrm{n} \sigma+\mathrm{m} \sigma}\right)^{3}
$$

in which $\sigma$ is the distance between neighbor centers in a chain; dipoles are numbered as $n, m=0,1,2 \ldots$ The total interaction energy is therefore

$$
\begin{aligned}
\frac{\mathrm{V}}{\mathrm{kT}} & =\frac{1}{\mathrm{kT}} \sum_{\mathrm{n}=0}^{\infty} \sum_{\mathrm{m}=0}^{\infty} \mathrm{V}_{\mathrm{n}, \mathrm{m}} \\
& =-2 \lambda \sum_{\mathrm{n}=0 \mathrm{~m}=0}^{\infty} \sum^{\infty}(\mathrm{l} / \sigma+\mathrm{n}+\mathrm{m})^{-3}
\end{aligned}
$$

The double summation contains $p+1$ identical terms for each value of $p=n+m$. Hence,

$$
\frac{\mathrm{V}}{\mathrm{kT}}=-2 \lambda \sum_{\mathrm{p}=0}^{\infty}(\mathrm{p}+1)(\mathrm{I} / \sigma+\mathrm{p})^{-3}
$$

For an approximatesolution, we consider chains at a large distance $(I \gg \sigma)$ and replace (9) by the integral

$$
\begin{aligned}
\frac{\mathrm{V}}{\mathrm{kT}} & \approx-2 \lambda \int_{0}^{\infty} \mathrm{dp}(\mathrm{p}+1)(\mathrm{I} / \sigma+\mathrm{p})^{-3} \\
& =-2 \lambda\left[\frac{1+\mathrm{I} / \sigma}{2(\mathrm{I} / \sigma)^{2}}\right]
\end{aligned}
$$

Figure 2 shows that eq 10 is a very good approximation of the interaction in eq 9 for $\mathrm{I} / \sigma>2$. Near contact at $\mathrm{I}=$ $\sigma$, theapproximation is incor rect; the contact energy from eq 9 is actually $V / k T=-2 \lambda(1.644)$, instead of $-2 \lambda$ from eq 10. The interaction eq 10 between the chain ends in Figure 1B is mainly determined by the dipoles adjacent to the "gap"; it is less important whether the ends bel ong to rigid linear chains or to one large ring which closes somewhere outside the box in Figure 1B. Thus eqs 9 and 10 are also relevant for folded chains (see section 4.2). Theconfinement by the bacteria opposes extensivebending of the chain. However, we expect that once rel eased from bacteria, a chain may close itself to a ring such that all head-to-tail interactions are "saturated". (This is actually theflux-cl osurering predicted by J acobs and Bean ${ }^{8}$.) Ring 
formation is counteracted by the energy required to bend a chain. For $n \geq 4$ dipoles, rings have a lower potential energy than chains. ${ }^{13}$ The difference, however, is small and vanishes for $n \rightarrow \infty$. A ring has nonet magnetic moment and is obvi ously unsuitablefor (bacterial) navigation. For this navigation, the energy $E$ of a linear chain of $n$ dipoles (with orientation $\hat{\mathbf{s}}$ ) in the earth magnetic field $\mathbf{H}$ (with orientation $\hat{\mathbf{s}}_{\mathbf{H}}$ ),

$$
\frac{\mathrm{E}}{\mathrm{kT}}=-\alpha\left(\hat{\mathbf{s}} \cdot \hat{\mathbf{s}}_{\mathbf{H}}\right) \quad \alpha=\frac{\mathrm{n} \mu_{0} u \mathbf{H}}{\mathrm{kT}}
$$

must be large enough. That is to say, the parameter $\alpha$ must satisfy $\alpha \gg 1$, becauseotherwisethechain orientation is easily pertur bed by thermal or convectivemotions. N ote that the orienting effects of $\mathrm{n}$ dipoles in eq 11 simply add up. However, the condition $n \gg 1$ does not necessarily imply that the bacteria havea good "compass". The vol ume $v_{p}$ of a magnetite crystal in eq 3 should not be too large to avoid multidomain formation but should neither betoo small toavoid thermal instability of themagneticmoment (superparamagnetism) which for magnetite occurs below a radius of roughly $10 \mathrm{~nm}$.

\section{Materials and Methods}

3.1. Bacterial Cultivation and Preparation. In exploring experiments, we cultivated Magnetospirillum gryphiswaldense (DSMZ, Germany). However, these experiments produced bacteria with a minority of only about $5 \%$ containing magnetite. Electron microscopy revealed that also in the cells supplied to us by DSM Z the percentage of magnetic bacteria is fairly low. Therefore, we choose to focus on another type of bacteria with a much higher percentage of magnetic cells.

M. magnetotacticum DSM 3856T was cultivated in a gel-like medium following a description in ref 14 which is based on several earlier reports.3,15,16 Tartaric acid, succinic acid, and sodium acetate are used as a carbon and energy source. The bacteria use ferricquinatefor theproduction of magnetite. Resazurineisused as an indicator for oxygen

For the growth medium, four different solutions were freshly prepared: a vitamin solution, a trace element solution, a ferric quinatesolution, and a resazurinesolution. The vitamin solution contained the following vitamins per liter of distilled water: 2.0 $\mathrm{mg}$ of biotin (Merck), $2.0 \mathrm{mg}$ of folic acid (Fluka), $10.0 \mathrm{mg}$ of pyridoxine $\mathrm{HCl}$ (OPG Farma), $5.0 \mathrm{mg}$ of thiamin-HCl (Fluka), $5.0 \mathrm{mg}$ of riboflavin (Fluka), $5.0 \mathrm{mg}$ of nicotinic acid (Merck), 5.0 $\mathrm{mg}$ of $\mathrm{D}, \mathrm{L}$-calcium pantothenate (Sigma), $0.1 \mathrm{mg}$ of vitamin $\mathrm{B}_{12}$ (Merck), $5.0 \mathrm{mg}$ of p-aminobenzoic acid (Fluka), and $5.0 \mathrm{mg}$ of lipoic acid (Fluka).

The trace element solution contained the following amounts of salts per liter of distilled water: $1.5 \mathrm{~g}$ of nitrilotriacetic acid (Fluka), $3.0 \mathrm{~g}$ of $\mathrm{MgSO}_{4} \cdot 7 \mathrm{H}_{2} \mathrm{O}$ (Fluka), $0.5 \mathrm{~g}$ of $\mathrm{MnSO}_{4} \cdot 2 \mathrm{H}_{2} \mathrm{O}$ (Merck), $1.0 \mathrm{~g}$ of $\mathrm{NaCl}$ (Merck), $0.1 \mathrm{~g}$ of $\mathrm{FeSO}_{4} \cdot 7 \mathrm{H}_{2} \mathrm{O}$ (Merck), $0.18 \mathrm{~g}$ of $\mathrm{CoSO}_{4} \cdot 7 \mathrm{H}_{2} \mathrm{O}$ (Fluka), $0.1 \mathrm{~g}$ of $\mathrm{CaCl}_{2} \cdot 2 \mathrm{H}_{2} \mathrm{O}$ (M erck), 0.18 $\mathrm{g}$ of $\mathrm{ZnSO}_{4} \cdot 7 \mathrm{H}_{2} \mathrm{O}$ (Merck), $0.01 \mathrm{~g}$ of $\mathrm{CuSO}_{4} \cdot 5 \mathrm{H}_{2} \mathrm{O}$ (Merck), 0.02 $\mathrm{g}$ of $\mathrm{KAl}\left(\mathrm{SO}_{4}\right)_{2} \cdot 12 \mathrm{H}_{2} \mathrm{O}$ (Merck), $0.01 \mathrm{~g}^{\circ} \mathrm{H}_{3} \mathrm{BO}_{3}$ (Merck), $0.01 \mathrm{~g}$ of $\mathrm{Na}_{2} \mathrm{MoO}_{4} \cdot 2 \mathrm{H}_{2} \mathrm{O}$ (Merck), $0.025 \mathrm{~g}$ of $\mathrm{NiCl}_{2} \cdot 6 \mathrm{H}_{2} \mathrm{O}$ (Merck), and $0.3 \mathrm{mg}$ of $\mathrm{Na}_{2} \mathrm{SeO}_{3} \cdot 5 \mathrm{H}_{2} \mathrm{O}$ (Merck).

The $0.01 \mathrm{M}$ ferric quinatesolution was prepared by dissolving $0.45 \mathrm{~g}$ of $\mathrm{FeCl}_{3} \cdot 6 \mathrm{H}_{2} \mathrm{O}$ (Fluka) and $1.9 \mathrm{~g}$ of quinic acid (Fluka) in $100.0 \mathrm{~mL}$ of distilled water. Finally, the resazurine solution was prepared by dissolving $0.1 \mathrm{~g}$ of resazurine (Fluka) in $100 \mathrm{~mL}$ of distilled water.

The gel-like growth medium consisted of (per $982.5 \mathrm{~mL}$ of distilled water) $10.0 \mathrm{~mL}$ of vitamin solution, $5.0 \mathrm{~mL}$ of trace element solution, $2.0 \mathrm{~mL}$ of ferric quinate solution, $0.5 \mathrm{~mL}$ of resazurine solution, $0.68 \mathrm{~g}$ of $\mathrm{KH}_{2} \mathrm{PO}_{4}$ (Merck), $0.12 \mathrm{~g}$ of $\mathrm{NaNO}_{3}$

(14) Deutsche Sammlung von Mikroorganismen und Zellkulturen (DSMZ, Germany, 1993).

(15) Maratea, D.; Blakemore, R. P. Int. J . Syst. Bacteriol. 1981, 31 (4), 452 .

(16) Wolin, E. A.; Wolin, M. J .; Wolfe, R. S. J . Biol. Chem. 1963, 238, 2882.
(BHD Chemicals Ltd), 0.05 g of sodiumthioglycolate(Fluka), 0.37 $\mathrm{g}$ of L-(+)-tartaric acid (M erck), $0.37 \mathrm{~g}$ of succinic acid (Fluka), $0.05 \mathrm{~g}$ of sodium acetate (Acros), and $1.3 \mathrm{~g}$ of agar (Difco Laboratories). All chemicals were used as supplied without further purification. The growth medium was prepared by dissolving the components in the order given above. Before addition of the agar, the $\mathrm{pH}$ of the medium was adjusted to 6.75 with $\mathrm{NaOH}$. The medium was boiled for $15 \mathrm{~min}$ to remove most of the oxygen. Portions of about $40 \mathrm{~mL}$ of medium were dispensed in screw-capped $100-\mathrm{mL}$ bottles. The bottles were crimp-sealed with a rubber stopper wired in place, and the atmosphere was replaced by $\mathrm{N}_{2}$. The bottles were autoclaved at $121^{\circ} \mathrm{C}$ for $15 \mathrm{~min}$.

After autod aving and cooling, sterile oxygen was added to the bottles, a few hours before inoculation, to provide $1 \%(\mathrm{v} / \mathrm{v}) \mathrm{O}_{2}$ in the gas phase. The media were slightly pink in col or. Cells were inoculated into the medium by injection through the stopper. Inocula contained approximately $1 \mathrm{~mL}$ (ca. $2 \times 10^{8}$ cells) per 40 $\mathrm{mL}$ of medium.

Bacteria weregrown at $30^{\circ} \mathrm{C}$. During growth, when theculture became reduced as evidenced by decolorization of the media, a small amount of oxygen and ferric quinate solution was added in order to obtain higher densities of magnetic cells. The cell concentration was determined by mi croscopicenumeration, using a Bürker-Türk counting chamber. ${ }^{17}$

3.2. Bacterial Cells. Transmission el ectron microscopy (TEM) was performed with a Philips $\mathrm{CM} 10 \mathrm{H}$ electron microscope operating at $80 \mathrm{kV}$. Samples were prepared by placing Cu grids, coated with a Formvar/carbon film, in a droplet of medium for a few minutes. The grids were dried in air.

Bacteria for elemental analysis were harvested from autoclaved media by centrifugation in a Beckman GS- 6 centrifuge for $20 \mathrm{~min}$ at $3000 \mathrm{rpm}$ and subsequently washed three times with distilled water. Elemental analysis was performed by induced coupled plasma atomic emission spectrometry (ICP) on a sample of magnetotactic cells, dried at $105^{\circ} \mathrm{C}$ toconstant weight.

Bacteria for electrophoresis were harvested from freshly autoclaved media by centrifugation in a B eckman GS-6 centrifuge for $20 \mathrm{~min}$ at $3000 \mathrm{rpm}$ and subsequently washed three times with distilled water and once with phosphate buffer, $\mathrm{pH}$ 7. The $0.05 \mathrm{M}$ phosphate buffer was prepared by dissolving $0.68 \mathrm{~g}$ of $\mathrm{KH}_{2} \mathrm{PO}_{4}$ (Merck) and $0.71 \mathrm{~g}$ of $\mathrm{Na}_{2} \mathrm{HPO}_{4}$ (M erck) in $1 \mathrm{~L}$ of distilled water. The electrophoretic mobility of cells in phosphate buffer was determined with a DELSA-440SX instrument (Coulter Electronics, Inc.) from the Doppler shift of scattered light from bacteria moved by the applied electric field.

Bacteria for analytical sedimentation experiments (under gravity) were harvested from freshly autodaved media by preparative centrifugation in a Beckman GS-6 centrifuge for 20 min at $3000 \mathrm{rpm}$ and subsequently washed three times with distilled water. After the dispersion was centrifuged for thethird time, the supernatant was removed and the cell mass was determined by drying a weighted amount of sediment at $105^{\circ} \mathrm{C}$ to constant weight. Nine cell suspensions were prepared by dispersing weighted amounts of sediment in phosphate buffer $(\mathrm{pH} 7)$ with final concentrations in the range of $0.24-0.48 \mathrm{mg}$ of cells per gram of dispersion. The sedimentation velocity of the cells under gravity was measured with a setup described in detail by Thies-Weesie. ${ }^{18}$ The dispersions were poured in glass sedimentation tubes of $1.5 \mathrm{~cm}$ diameter and $30 \mathrm{~cm}$ length, which were carefully closed. Settling of particles is easily disturbed by even minute vibration or temperature variations. ${ }^{18}$ Therefore, the sedimentation tubes were immersed precisely vertically in a water bath on a heavy marble table in a thermostatic room with constant temperature $\left(T=21.5 \pm 0.1^{\circ} \mathrm{C}\right)$. The descent of the dispersion-solvent interface was measured for $70 \mathrm{~h}$. To increase the visibility of the interfaces, the sedimentation tubes were placed in front of a black background. After $70 \mathrm{~h}$, the dispersions were homogenized by shaking and the settling experiment was repeated. Each sample was measured three times, and theresulting sedimentation vel ocities wereaveraged.

Magnetization measurements were done with an alternating gradient magnetometer (AGM, MicroMag 2900 of Princeton

(17) Gerhardt, P. Manual of Methods for General Bacteriology; American Society for Microbiology: Washington, DC, 1981.

(18) Thies-Weesie, D. M. E.; Philipse, A. P.; Lekkerkerker, H. N. W. J . Colloid Interface Sci. 1996, 177, 427. 
Measurements Corp.). The magnetic moment of a sample was measured as a function of thestatic magnetic field strength which ranged from -0.5 to $0.5 \mathrm{~T}$. (By applying an alternating field gradient on a magnetized sample, an al ternating forceis produced which is proportional to the magnetic moment of the sample.) The sample for magnetization measurements was prepared by drying a dispersion of magnetotactic bacteria in distilled water at $105^{\circ} \mathrm{C}$ to constant weight. The dried sample was wrapped in Scotch tape and stuck tothesample probe. F urther details about sample preparation and analysis can be found in refs 7 and 20 .

3.3. Bacterial Magnetite Particles. The first method we used to extract magnetite particles from cells was sonication following $\mathrm{F}$ rankel ${ }^{21}$ and others. ${ }^{22,23}$ Cells dispersed in distilled water were sonicated for 12 min with a Soniprep 150 sonicator at an amplitude of 10 microns. The sonicated samples were centrifuged in a preparative ultracentrifuge (Beckman L-60) for $20 \mathrm{~h}$ at $8000 \mathrm{rpm}$. The magnetite particles were washed three times in distilled water. Magnetic particles were col lected at the vessel wall with a bar magnet.

The second method to disrupt cells and collect magnetic particles empl oys a sodium hydroxidesolution foll owing $\mathrm{Fr}_{\text {rankel }}{ }^{21}$ and M atsunaga. ${ }^{23}$ Growth medium with a high cell concentration was poured into a beaker and stirred. Sodium hydroxide platelets were added to the dispersion up to a concentration of $5 \mathrm{M} \mathrm{NaOH}$. After stirring for approximately $16 \mathrm{~h}$, the samples were centrifuged in a preparative ultracentrifuge (Beckman L-60) for $10 \mathrm{~h}$ at $8000 \mathrm{rpm}$. The magnetic particles were washed three times in distilled water and collected with a magnet.

TEM was performed as in section 3.2. The surface area of about 100 particles was measured with an interactive image analysis system to determine the average equivalent sphere diameter.

Elemental analysis was performed by instrumental neutron activation analysis (I NAA) on magnetite particles extracted from cells by washing with a sodium hydroxide solution followed by magnetic purification. Thesamplewas dried at $105^{\circ} \mathrm{C}$ to constant weight. (INAA was used instead of ICP because the amount of magnetite was insufficient for ICP analysis.)

Magnetization measurements on magnetite particles were performed as in section 3.2. The particles were extracted from cells by washing with a sodium hydroxide solution followed by magnetic purification. The sample was dried to constant weight at $105^{\circ} \mathrm{C}$.

Atomic and magnetic forcemicroscopy imaging was donewith a Nanoscope III Dimension 3000 scanning probe (Digital Instruments). The probe consists of a magnetically coated Nanoprobe tip. First, a surface topography image was obtained using the tapping mode, and then a magnetic force image was taken using the liftmode. In the liftmode, the probe is lifted and follows the same height pattern as al ready measured in the topographical scan. The samples were prepared by drying a droplet of distilled water containing magnetite partides, extracted from cells by washing with a sodium hydroxide solution, on mica platelets.

\section{Results and Discussion}

4.1. Bacterial Cultivation and Preparation. Inoculation of $\mathrm{M}$. magnetotacticum in a gel-like medium in sealed 100-mL bottles produced within a week diffuse, fluffy areas of growth a few centimeters below the medium-air interface. Then the bacteria started to grow upward in the direction of the surface, leading to the reduction of the medium as evidenced by the disappearance of the pink (resazurine) color. By addition of oxygen and ferric quinate during growth, higher densities of magnetic cells were obtained as could be verified by

(19) Donselaar, L.; Frederik, P. M.; Bomans, P.; Buining, P. A.; Humbel, B. M.; Philipse, A. P. J . Magn. Magn. Mater. 1999, 201, 58.

(20) Instruction manual of MicroMag 2900 Alternating Gradient Magnetometer; Princeton Measurements Corp.: Princeton, NJ , 1993.

(21) Frankel, R. B.; Papaefthymiou, G. C.; Blakemore, R. P.; O'Brien, W. Biochim. Biophys. Acta 1983, 763, 147.

(22) Denham, C. R.; Blakemore, R. P.; Frankel, R. B. IEEE Trans. Magn. 1980, 16 (5), 1006.

(23) Matsunaga, T.; Tadokoro, F .; Nakamura, N . I EE E Trans. Magn. 1990, 26 (5), 1557 transmission el ectron microscopy. In about 2 weeks, the population increased from an initial density of about $5 \times$ $10^{6}$ cells per milliliter to a final concentration of $10^{8}$ to 2 $\times 10^{8}$ cells per milliliter. Approximately $70 \%$ of the cells produced magnetite particles. Since we managed to cultivate $M$. magnetotacticum on a small scale, we attempted an upscaling to (seal ed) 1-L bottles. However, generally the final population density in the 1-L bottles was lower and al so the percentage of magnetic cells was much lower than in the 100-mL bottles. Possibly theyield can beimproved by keeping the oxygen and fer ric quinate concentration and the $\mathrm{pH}$ of the medium constant during growth.

4.2. Imaging and Particle Structures. Electron micrographs of M. magnetotacticum (grown in 100-mL bottles) are shown in Figure 3. The cell diameter is in the range of $0.2-0.4 \mu \mathrm{m}$, and the cell length is $4-6 \mu \mathrm{m}$. About $70 \%$ of the cells contains magnetite particles, which are aligned in a chain parallel to thel ong axis of the bacteria. Occasionally al so a "branched" chain is observed as shown in Figure 3a. The number of particles in the cells varies from 0 to 45 . It is indeed possible to extract magnetite particles from bacterial cells by sonication as well as by washing with a sodium hydroxide solution. Magnetophoresis sometimes is effectiveto separate the magnetite crystals from organic material (F igure 4), though in other cases a substantial organic residue remains (Figure $4 \mathrm{~g}$ ).

Individual bacterial magnetite particles, which are reported to be cubo-octahedrons, ${ }^{26}$ seem to have a somewhat irregular facetted shape. The average surface area of harvested magnetic particles on the TEM pictures is $5.5 \times 10^{4} \mathrm{~nm}^{2}$ with a polydispersity of $24.8 \%$. The mean equivalent sphere diameter is $47.1 \mathrm{~nm}$ with a polydispersity of $13.3 \%$. Dimensions of cells and magnetite particles (Tables 1 and 2) are in good agreement with literature values. ${ }^{3,24-26}$

The surface topographic and magnetic force images of dried magnetite particles are shown in Figure 5. The surface topographic force image shows differences in height of thesamplesurfaceas measured by thecantilever. The surface topographic image (right) and the magnetic force image (left) show strings of magnetic particles.

The magnetite crystals are single domains with a thermally stable magnetic moment. These magnetic moments are large ( $\lambda$ is about 70 , see section 4.6$)$, so when thecrystals areconfined tolieon a two-dimensi onal plane (in this casea TEM grid), themoments will orient parallel to the plane such that head-to-tail contacts can be made. The rings in Figure 4c-e are therefore very likely fluxclosure rings of in-plane dipoles, possibly the first images of the J acobs-Bean ${ }^{8} \mathrm{flux}$-closure rings for $\mathrm{Fe}_{3} \mathrm{O}_{4}$ colloids. In conventional magnetite ferrofluids, $\lambda$ is too small for particles to form such large rings and long chains as in Figure 4c-e. We refer here to a cryo-electron microscopy study ${ }^{19}$ on magnetite ferrofluids, in which magnetite particles (typical radius, $5 \mathrm{~nm}$ ) were shown to have a tendency to form more or less isotropic clusters. This tendency was also partly ascribed to the isotropic van der Waals attractions, ${ }^{19}$ which may significantly affect the association behavior in a ferrofluid. Since the magnetic attractions increase much faster with particlevolume (see eqs $1-3$ ) than van der Waals forces, the latter hardly contributefor suffiently largeparticles, which is certainly

(24) Schleifer, K. H.; Schuler, D.; Spring, S.; Weizenegger, M.; Amann, R.; Ludwig, W.; Kohler, M. Syst. Appl. Microbiol. 1991, 14, 379.

(25) Balkwill, D. L.; Maratea, D.; Blakemore, R. P.J . Bacteriol . 1980, 141 (3), 1399. 405. 

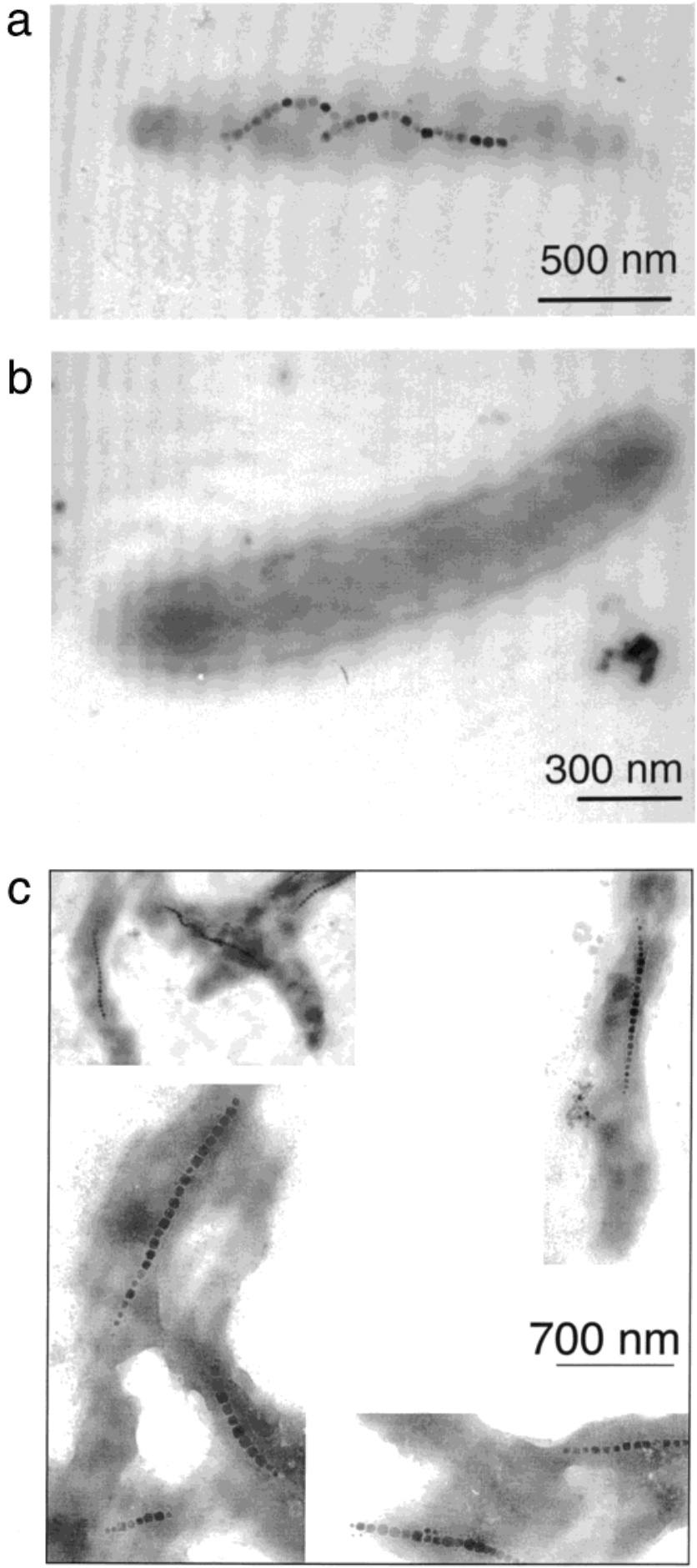

Figure 3. Transmission el ectron micrographs of (a) a magnetotactic cell (M. magnetotacticum, as for all pictures), (b) a nonmagnetotactic cell, and (c) groups of cells with magnetic backbones.

the case for the colloids in Figure 4. The dominance of magnetic attraction is also clearly illustrated by Figure 4d. Heretheparticles got stuck on theTEM gridat particle surface-to-surface distances up to one particle diameter. Nevertheless, theringstructurehas been preserved. N ote that breaking a large ring will cost nearly the same dissociati on energy as breaking a straight chain. Thus eq 10 can be applied to conclude that for $\lambda \sim 70$ a chain will have a strong tendency to "snap" to a ring al ready when its ends are still several particle diameters apart. The lowest energy state for a largenumber of in-planedipoles
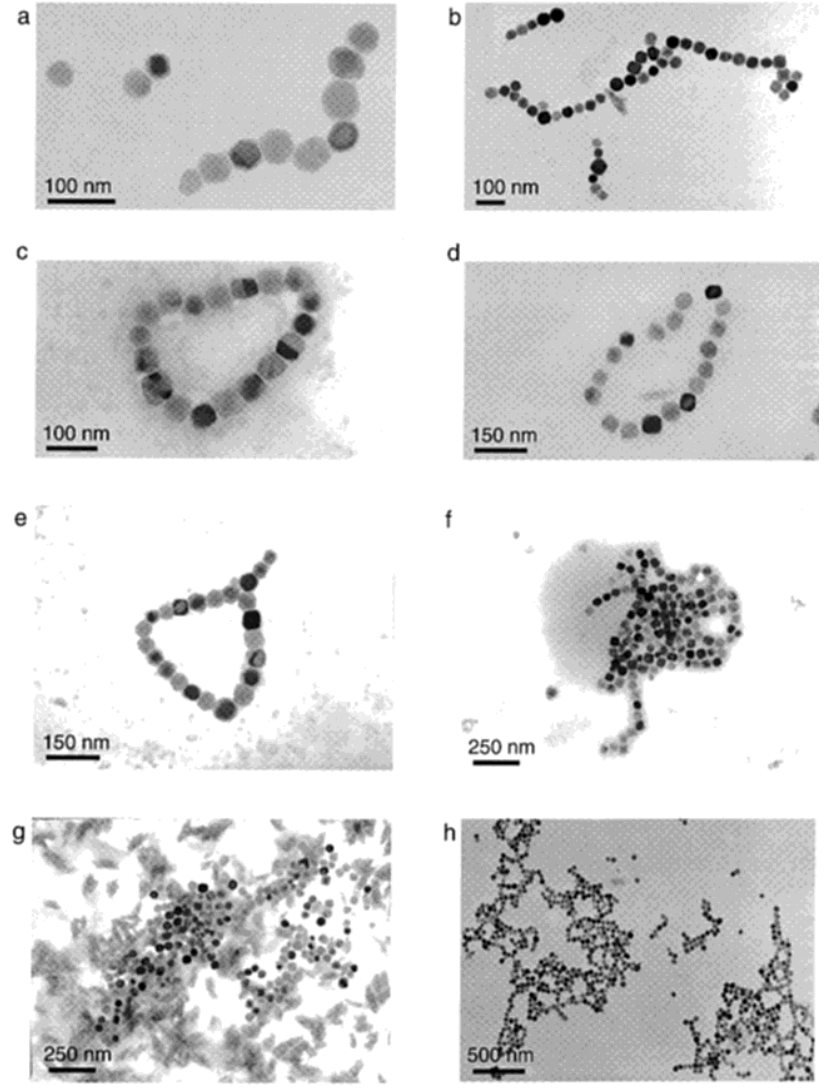

Figure 4. Representative selection of cluster morphologies for magnetite $\left(\mathrm{Fe}_{3} \mathrm{O}_{4}\right)$ colloids extracted from cells imaged by transmission electron micrographs. Note the magnetic fluxclosure rings in images $c, d$, and e. The tendency of forming stringlikeaggregates can becl early seen in for example images $b$ and $f$.

Table 1. Properties of (Dried) Bacterial Cells

\begin{tabular}{ll}
\hline length & $4-6 \mu \mathrm{m}$ \\
diameter & $0.2-0.4 \mu \mathrm{m}$ \\
fraction magnetotactic cells & $70 \%$ \\
number of magnetite particles & $0-45$ \\
Fe concentration & $1.8 \mathrm{mg}$ per gram dry weight \\
remanent magnetization $\mathrm{M}_{\mathrm{r}}$ & $2.77 \mathrm{nA} / \mathrm{m}$ \\
coercive field $\mathbf{H}_{\mathrm{c}}$ & $13.8 \mathrm{mT}$ \\
maximum magnetization $\mathrm{M}_{\mathrm{s}}$ & $13.4 \mathrm{nA} / \mathrm{m}$
\end{tabular}

Table 2. Properties of (Dried) Magnetite Colloids

$\begin{array}{ll}\text { mean (equivalent) diameter } & 47.1 \mathrm{~nm} \\ \text { polydispersity } & 13.3 \% \\ \text { Fe concentration } & 9 \mathrm{mg} \text { per gram dry weight } \\ \text { remanent magnetization } \mathrm{M}_{\mathrm{r}} & 14.4 \mathrm{nA} / \mathrm{m} \\ \text { coercive field } \mathbf{H}_{\mathrm{c}} & 8.13 \mathrm{mT} \\ \text { maximum magnetization } \mathrm{M}_{\mathrm{s}} & 53.9 \mathrm{nA} / \mathrm{m}\end{array}$

is one circular ring. However, deformations easily occur because of screening of dipolar interactions, which weakens the force between opposite ring parts considerably. These shape deformations can be observed in Figure 4c,d.

A peculiar morphology is the "handl e"-shaped cluster, an example of which is depicted in Figure 4e. Such handles could be chains, which have folded back unto themselves but not far enough to form a ring. Note that the handle is metastable with respect to a ring, which saturates all dipoles. A handle may also result from the encounter between a closed ring and a linear chain. Figure $4 \mathrm{~h}$ is an illustrative example of a TEM micrograph of a larger population density of magnetite colloids. A free singlet, as expected for strong dipoles, is a rare event; most particles formaggregates in which strings, deformed rings, 


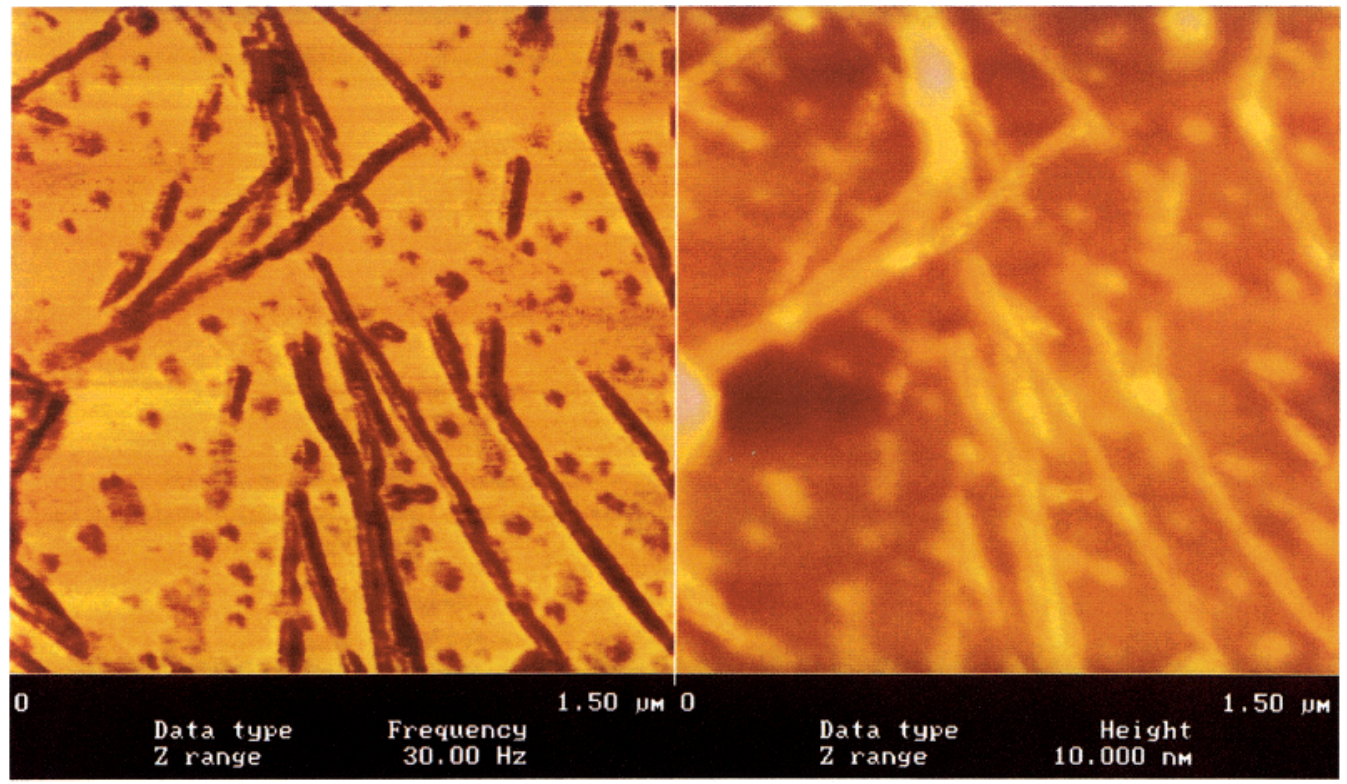

Figure 5. Atomic force microscopy: topographic (right) and magnetic (left) images of magnetic particles extracted from cells.

and handles are present on a local scale involving 10-20 particles. The global image, of course, may be influenced by capillary or shear forces in the preparation of TEM grids. The cluster morphology, nevertheless, resembles simulation snapshots of strongly polar fluids, showing nucleation of dipolar sphere structures which look very similar to Figure $4 f .{ }^{11}$

4.3. Elemental Analysis. The presence of iron in the purified bacteria samples is confirmed by the elemental analysis results. The iron concentration in the bacterial cells, determined with ICP, is about $1.8 \mathrm{mg}$ per gram dry weight. (Blakemore ${ }^{3}$ reports in magnetic cells iron concentrations of $20 \mathrm{mg}$ per gram dry weight.) In a small amount of magnetite particles extracted from cells by washing with sodium hydroxide solution, the iron concentration determined with INAA is roughly $9 \mathrm{mg}$ per gram dry weight. In pure magnetite, the iron weight concentration is about $70 \%$; in the sample of magnetite particles extracted from cells, we found a concentration of about $1 \%$. So it can beconcluded that magnetite particles extracted from cells and collected with a bar magnet still may contain a relatively largeamount of organicmaterial. Part of theorganic material may stem from magnetosome membranes around themagnetic particles. Such residues, incidently, are difficult to image with TEM, a technique which is rather insensitive to low-contrast organic material.

4.4. Electrophoresis. Theel ectrophoresis experiments for the bacterial cells in phosphate buffer show that the cell walls carry negative surface charge at neutral $\mathrm{pH}$. Thesurfacecharge of the bacteria originates from carboxyl, phosphate, and amino groups. The degree of dissociation of these ani onic and cationi c groups is determined by the $\mathrm{pH}$ and theactivity of thesurrounding electrolytesolution. Usually bacterial cells are negatively charged at neutral $\mathrm{pH}$, becausethenumber of carboxyl and phosphategroups is generally higher than that of the amino groups. ${ }^{27}$

The ionic strength in our samples is high, so the Debye length is very much smaller than bacterial dimensions. Thus one could attempt to use the classical HelmholtzSmoluchowski theory ${ }^{27}$ for the conversion of the electro-

(27) Wal, A. van der Electrochemical characterization of the bacterial cell surface. Ph.D. Thesis, Wageningen University, Wageningen, The Netherlands, 1996.

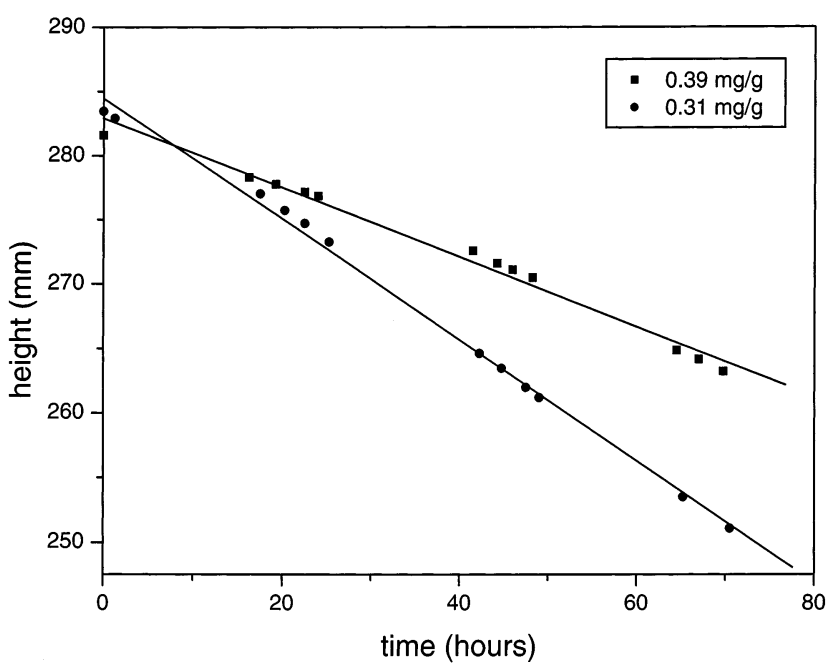

Figure 6. Typical sedimentation results showing the height of theinterface between themagnetotacticcells sand supernatant (phosphate buffer) versus time, for two bacterial mass concentrations ( 0.31 and $0.39 \mathrm{mg} / \mathrm{g})$. Thesolid lines are linear fits.

phoretic mobility into the $\xi$-potential, which in our case leads to a $\xi$-potential of order $1 \mathrm{mV}$. However, in this theory it is assumed that the ionic atmosphere of the electrical double layer is not deformed by the external electric field. This assumption holds as long as the conduction of ions along or in the particle surface is negligibly small. For bacterial cells, however, surface conduction effects may be considerable, even at low $\zeta$-potentials, depending on the amount of mobile ions in the bacterial wall. ${ }^{27}$ Thus for bacterial cells actually no reliable estimate for the magnitude of $\xi$-potential from electrophoretic mobility can be obtained, unless quantitative information on the cell wall conductivity is available.

4.5. Gravitational Sedimentation. During the sedimentation of the magnetotactic cells, a sharp, somewhat bumpy interface was observed between the dispersion and the clear supernatant. In all measurements, the height of theinterface descends linearly with time. Figure 6 shows typical results for two mass concentrations. After sedimentation and shaking, the samples showed no flocs or other inhomogeneities indicative of permanent particle coagulation. The bacteria redispersed easily, and the 


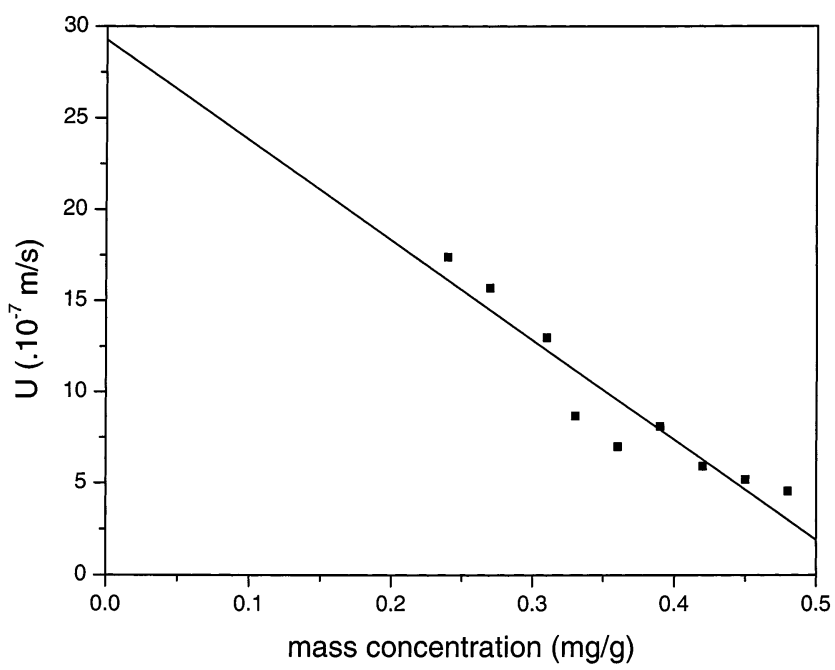

Figure 7. The sedimentation velocities $U$ versus the mass concentration obtained from data as in F igure 7. The solid line is a linear fit.

settling data were reproduci ble. This reproducibility is a sensitivetest for thecolloidal stability of thecells, because sedimentation vel ocities and their reproduci bi lity arevery sensitive to even weak attractions or aggregation. ${ }^{28}$

The sedimentation velocity $U$ as a function of the bacterial mass concentration is plotted in Figure 7. The single-bacteria velocity $U_{0}$ is found from extrapolation to infinite dilution to be $\mathrm{U}_{0}=2.9 \times 10^{-7} \mathrm{~m} \mathrm{~s}^{-1}$. Figure 7 shows that the sedimentation vel ocity decreases linearly with increasing mass concentration. This linear decrease can be expected for stable colloids with a short-range interparticlerepulsion. ${ }^{29} \mathrm{I} \mathrm{n}$ a phosphatebuffer, the doublelayer repulsion between the negative charged bacteria indeed must be of very short range in comparison to the bacteria dimensions. Nevertheless, magnetic or van der Waals attractions due to the iron oxide "backbones" are still masked, because otherwise the sedimentation rate would increase with concentration, a well-documented phenomenon for attractive colloids. ${ }^{29}$ We note that this positive concentration dependence does not necessarily require permanently aggregated particles. An increased probability for particles to sediment temporarily as a doublet may suffice. The first-order dependence of $U$ on weight concentration c,

$$
\mathrm{U}=\mathrm{U}_{0}-\mathrm{kc}
$$

can be rewritten as

$$
\frac{\mathrm{U}}{\mathrm{U}_{0}}=1-\mathrm{H} \varphi \quad \mathrm{H}=\mathrm{k} \delta / \mathrm{U}_{0}
$$

for a volume fraction $\varphi$ of bacteria with mass density $\delta$. For nonspherical colloids, theoretical expressions for $\mathrm{H}$ are not available, ${ }^{29}$ with the exception of thin, rigid rods. For such rods sedimenting in a random orientation, Dhont recently derived that $\mathrm{H}$ varies as ${ }^{30}$

$$
H \propto(L / D)^{2} / \ln (L / D) \quad \text { for } L / D \gg 1
$$

in which L/D is the rod aspect ratio. Of course, a thin,

(28) Thies-Weesie, D. M. E. Sedimentation and liquid permeation of inorganic colloids. Ph.D. Thesis, Utrecht University, Utrecht, The Netherlands, 1995

(29) Philipse, A. P. Curr. Opin. Colloid Interface Sci. 1997, 2, 200.

(30) Dogic, Z.; Philipse, A. P.; Fraden, S.; Dhont, J . K. G. J . Chem.

Phys. 2000, 113, 8368.

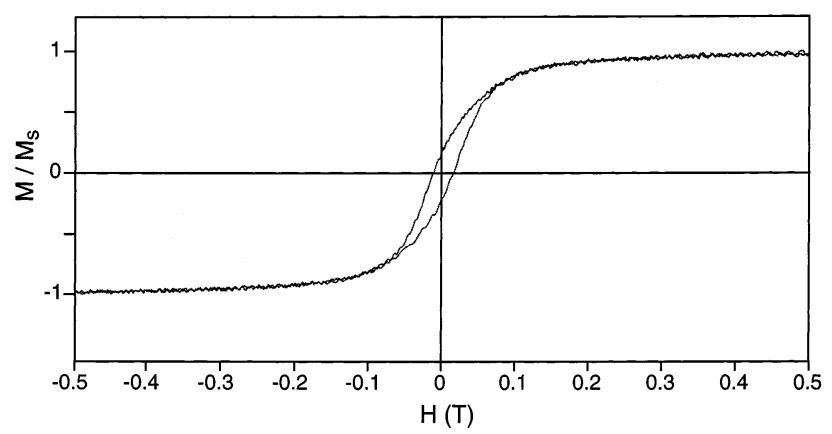

Figure 8. Normalized magnetization $M / M_{S}\left(M_{S}\right.$ is the measured saturation magnetization at high field) of dried magnetite particl es extracted from cells versus theapplied magnetic field $\mathbf{H}$.

rigid rod is a poor (hydrodynamic) approximation for bacterial shapes as in Figure 3. However, eqs 13 and 14 confirm the idea that the settling of nonaggregated elongated objects has a negative concentration dependence.

4.6. Magnetic Properties. Magnetization measurements with the alternating gradient magnetometer are shown in Figure8, depicting thenormal ized magnetization $M / M_{S}$ versus the applied magnetic field $\mathbf{H}$ for dried magnetite particles extracted from cells. (For dried bacterial cells, the curves look very similar.) The value of the magnetization at zero field, the remanent magnetization $M_{r}$, and themagnitudeof thefield that must beapplied in the negative direction to bring the magnetization back to zero, the coercive field $\mathbf{H}_{c}$, are given in Tables 1 and 2 . Thesemeasurements confirm that themagnetite particles produced by the bacterial cells are not superparamagnetic. Whether the magnetic particles are single domain or multidomain cannot be seen in Figure 8. However, for magnetite it is reported that the minimum size at which a particle becomes a multidomain lies between 80 and $120 \mathrm{~nm}^{3}$. Bacterial magnetite has a diameter of $47.1 \mathrm{~nm}$, bel ow the critical size for multidomain formation. This is hardly surprising since the chain of magnetic particles will work as a biocompass only if the particles are single domains.

The formation of chains and rings requires that the contact energy between magnetosomes is large. F or a bare magnetite sphere with radius $\mathrm{R}=20 \mathrm{~nm}$, we find, using eq 2 , that $\lambda \approx 70$, using the bulk magnetization $\mathrm{m}_{\mathrm{s}} \approx 400$ $\mathrm{kA} / \mathrm{m}$. This is a substantial attraction, which is not very much weakened if we incorporate the "screening effect" of the lipid layer by a realistic choice of $\Delta=2 \mathrm{~nm}$ in eq 2 , leading to $\lambda \approx 53$.

4.7. Interbacteria Interactions. In our buffer solutions (and in their natural aqueous environment), the Debyescreeninglength is toosmall to causeany significant electrical double-layer repulsion between the bacteria; there is apparently only a short-range excluded volume repulsion which forbids bacteria to interpenetrate. Then the question arises of why long-range dipole-dipole attractions, strong enough to arrest magnetite particles permanently in a chain with a large total magnetic moment, do not aggregate the bacteria. Indeed, our eq 10 predicts a significant attraction if two magnetite chains would nearly make contact in a head-to-tail configuration as in Figure 1b. Probably such an approach will not be cl ose enough to produce aggregation because usually the bacteria are much longer than their magnetic chains. In a parallel bacteria orientation, however, the chains may bein someinstances just a few magnetitediameters apart. Sedimentation results, nevertheless, indicate that side- 


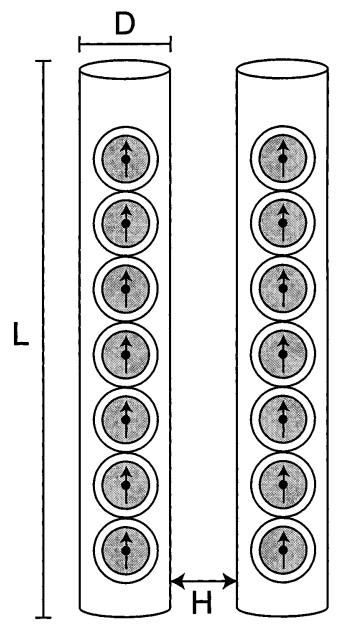

Figure 9. Model used to estimate the attraction between two parallel bacteria due to their magnetite backbones. The dipole chains form the main axis of a nonmagnetic cylindrical shell that determines the distance (D) of closest approach between the dipole centra. $\mathrm{H}$ is the surface-to-surface distance of the cylinders.

wise aggregation does not occur. The reason for this stability is very likely theconsi derablescreening of di polar forces between parallel chains. Toquantify this statement, we will model two bacteria as two parallel cylinders with a rigid dipole chain at the main axis. The interaction energy between two parallel, rigid dipole chains of length $\mathrm{L} \gg \sigma$ at a distance $x$ (Figure 9) has been calculated by Halsey and Toor. ${ }^{10}$ Their result is

$$
\mathrm{V} / \mathrm{kT}=2 \lambda \mathrm{n} 4 \pi^{2}(\sigma / \mathrm{x})^{1 / 2} \exp [-2 \pi \mathrm{x} / \sigma] \cos (2 \pi \mathrm{h} / \sigma)
$$

where $\mathrm{h}$ is the parallel shift of one chain with respect to the other; $\mathrm{L} / \sigma=\mathrm{n}$ is the number of dipoles in a chain. For $\mathrm{h}=\mathrm{z} \sigma(\mathrm{z}=0,1,2, \ldots)$, the chains repel each other. For $\mathrm{h}$ $=(z+1 / 2) \sigma$, there is an attraction:

$$
\mathrm{V} / \mathrm{kT}=-2 \lambda \mathrm{n} 4 \pi^{2}(\sigma / \mathrm{x})^{1 / 2} \exp [-2 \pi \mathrm{x} / \sigma]
$$

Comparing this result with the dipolar interaction in eqs 1 and 2, we see that the chain-chain attraction is indeed strongly screened. The screening resembles a Yukawa potential with screening length $\sigma / 2 \pi$. So even for strong intrachain interactions $(\lambda \gg 1)$ theinterchain interactions are al ready insignificant at interchain distances of order $\mathrm{x}=\sigma$. This implies that parallel magnetotactic bacteria do not experience each other's magnetic backbone. Of course, also van der Waals attractions between the iron oxide chains should be taken into account, because such oxides in water have a large Hamaker constant. ${ }^{31}$ We thereforemodel thetotal attraction between two magnetite chains as a sum of dipolar forces (eq 16) and van der Waals attractions. We take two chains of 45 magnetite particles with $\sigma=47 \mathrm{nmsoL}=2115 \mu$ mand evaluatetheinterchain attraction using eq 16 (Figure 10). The van der Waals force between the two parallel magnetic cylinders is calculated from the expression of Sparnaay ${ }^{31,32}$ using A = $10^{-19} \mathrm{~J}$ as an upper estimate of the Hamaker constant for iron oxide in water at room temperature. ${ }^{31}$ It turns out

(31) Lyklema, J . Fundamentals of Colloid And Interface Science; Academic Press: London, 1993; Vol. I.

(32) Sparnaay, M. J . Recl. Trav. Chim. 1959, 78, 680.

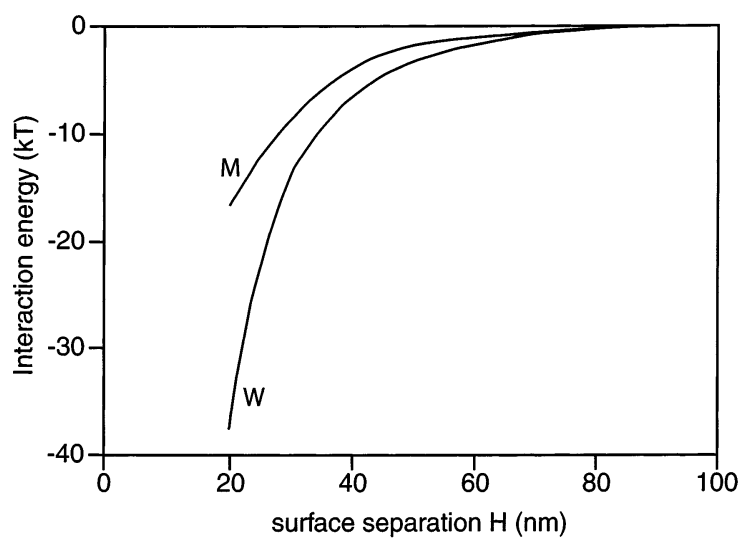

Figure 10. Magnetic attraction $(M)$ and van der Waals attraction $(\mathrm{W})$ between two parallel magnetitechains of length $\mathrm{L}=2.115 \mu \mathrm{m}$ and aspect ratio $\mathrm{L} / \mathrm{D}=45$.

(F igure10) that thetotal attraction (which in our example is actual ly dominated by the van der Waals force) quickly vanishes for surface-to-surface distances $\mathrm{H}=\sigma=47 \mathrm{~nm}$. Since a typical bacterial diameter is in the range of 200$400 \mathrm{~nm}$, we can conclude that parallel magnetite chains do not affect the colloidal stability of the bacteria.

\section{Conclusions}

We have cultivated the magnetotactic bacterium $\mathrm{M}$. magnetotacticum on a milligram scale in the laboratory. The negatively charged bacterial cells contain 0-45 magnetite particles, which arealigned in a chain parallel to the longitudinal axis of the cell. The single-domain magnetite colloids harvested from the bacteria form structures such as flux-closure rings of in-plane dipoles and folded chains of the type predicted for colloids with domi nant dipolar forces. Such structures clearly resemble the morphologies observed in simulations of strongly dipolar spheres. From sedimentation experiments, we conclude that the net attraction between chains of magnetic particles is toosmall to produceany aggregation of bacteria. Theforce between parallel bacterial magnetite backbones is strongly screened, in contrast to the interaction of a single chain with an external field where effects of dipoles add up: the bacteria sense the geomagnetic field but not each other's compass.

Acknowledgment. N. Tan is acknowledged for his explorativestudy in our group on growth of magnetotactic bacteria. W. Bitter (Molecular Cell Biology, Utrecht University) and C. Pathmamanoharan are thanked for helpful discussions. L. Donselaar, A. George (NMRspectroscopy, Utrecht University), and A. Ürmenyi are thanked for performing magnetization, sonication, and electrophoresis experiments, respectively.J . Flach (Digital Instruments, Sliedrecht, The Netherlands) performed MAFM measurements. B. J . de Gans and D. Derks contributed to the cal culations in section 2. M. Lanen, M. Uit de Bulten, J . den Boesterd, and I. van Rooyen are thanked for their help in preparing the manuscript. A.P. recalls with pleasure discussions with] . Moonen on animal navigation. Part of the investigation was supported by TheN etherlands F oundation for Chemical research (SON) with financial aid from The Netherlands Organization for Scientific Research (NWO).

LA0205811 